\title{
Letter from . . . Thailand
}

\section{Primary health care in Ubon refugee camp}

\author{
JOHN O'SULLIVAN，GERALDINE O'SULLIVAN， SHAH EBRAHIM
}

On 17 August 1979, Ubon Refugee Camp in the north-east of Thailand celebrated its fourth anniversary with a brief Buddhist ceremony. In these four years just over 6000 refugees have been resettled in other countries, mainly the United States of America and France. There were then 13 other refugee camps in Thailand populated by Laotian, Cambodian, hill-tribe, and Vietnamese refugees. Ubon camp is one of the largest-an

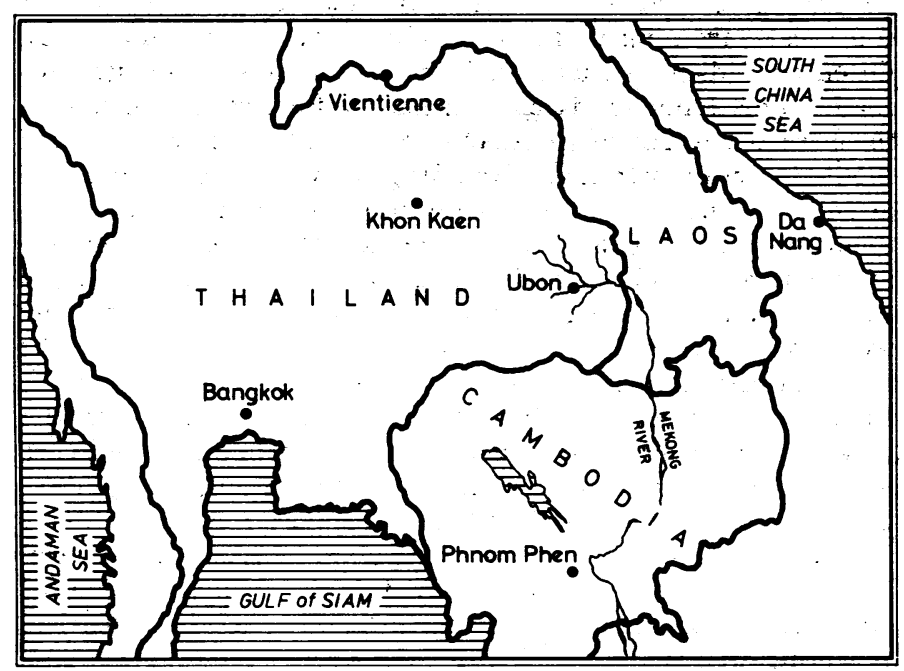

increase of 12000 in the last year has brought the number of Laotians to nearly 40000 (though many will tell you privately that there are a few thousand more). Thailand has about 100000 Laotian refugees, but their plight has been overshadowed by the more dramatic events surrounding the Vietnamese and Cambodians.

Ironically, Ubon Refugee Camp has grown up on the site of a former US Air Force ammunition dump. Thanks to its previous tenants, the terrain is flat, dotted with bunkers, and has excellent tarmac roads. According to their social position, the refugees live in either self-constructed bamboo and grass huts or United Nations-built wooden barns, which each house about 500 people.

Some people are able to run businesses such as grocery shops, cafes, and pharmacies. The pharmacies may be particularly dangerous as they are run by unqualified staff and there are virtually no controls on purchasing drugs in Thailand. Most of the refugees keep ducks or hens and have vegetable gardens now that they realise resettlement may be interminably slow. The majority, however, have little to occupy their time.

Lao Refugee Camp Clinic, Ubon, Thailand

JOHN O'SULLIVAN, DRCOG, DCH, medical officer of health

GERALDINE O'SULLIVAN, BA, DMRD, medical team member

Faculty of Medicine, Khon Kaen University, Thailand

SHAH EBRAHIM, BM, DCH, adviser in community medicine

\section{Health services}

Ubon camp is unusual in that it has no hospital. This arose partly by design and partly because when the camp began and was small the refugees were treated at home. As the camp grew, the medical services were centred on public outpatient sessions held in an open wooden structure. Because the clinic and domiciliary services were so public, the curiosity and interest of the refugees were aroused and many volunteers offered their help to the six-member European team. Hence, each European doctor or nurse heads a group of volunteers each engaged in a particular aspect of health care. The three nurses run the infant welfare, midwifery, and public health units, which all demand extensive home visiting. Meanwhile, the doctors, with their volunteer helpers, conduct the outpatient clinics emphasising paediatrics, tuberculosis treatment, gynaecology; and family planning.

The clinic has 10 beds that are used only overnight for those requiring intravenous treatment, and nursing care is left to the relatives. Any development of these overnight facilities towards a hospital-type service would mean a great increase in costs and professional staffing. Like the other camps in Thailand, Ubon can refer refugee patients to the local Thai provincial hospital in certain circumstances-for example, surgical emergencies, urgent medical problems, and psychiatric cases. From 7000 patient-consultations made in the clinic each month about 100 referrals are necessary. The other camps that did develop hospital facilities never produced as much of a reduction in morbidity as occurred in Ubon. Despite the increasing population in Ubon, in 18 months drug costs fell from $£ 2500$ a month to about $£ 1800$ a month because of a strict prescribing policy and reduced morbidity.

\section{Volunteer health workers}

Over 70 refugees help the European team in Ubon. The helpers were selected from the many people offering their services and were chosen either because of previous medical experience or possession of some special talent. About half had received some medical training in Laos, whereas the rest were a mixture of linguists, experienced mothers, farmers, and engineers. One was a fully qualified doctor. There are also experienced midwives, laboratory technicians, and surgical nurses who require little further training and run basic services guided by a European team member. Because of gradual resettlement each is required to train a replacement. Other volunteers, the paramedics and those working in the infant welfare clinic, mostly had no medical experience.

\section{PARAMEDICS}

Because selective resettlement of the most talented refugees has depleted trained medical personnel, the Thai Red Cross started a programme of two-month theoretical courses followed 
by practical training in the camps. The training concentrated on basic nursing and public health to produce a type of "barefoot doctor." Sixteen people were chosen from Ubon; those chosen were literate, compassionate, and unlikely to be resettled. Over the last year, of the original 16, five dropped out and three were resettled, but the remaining eight blossomed after some surprising initial difficulties. The first problem was one of recognition, not only by refugees but also by the trained Laotian staff, who tended to look down on them. This was solved by giving them a uniform (nobody else had one), almost continuous supervision by a European nurse, and time. A major problem was to persuade them to leave the clinic and work in the camp. This was resolved by getting them to complete survey forms, which made them visit each family in certain areas of the camp.

Quite fortuitously, while the paramedics were doing the survey, the United Nations High Commission for Refugees office supplied 20000 blankets and mosquito nets. The distribution was done by the paramedics and led to an immediate rise in status. Since then they have resited spoilt wells, carried out health education, and completed a nutritional survey (using arm circumference measurements) of over 2000 children. More recently they have been entrusted with the vaccination programme, and given drugs such as aspirin and glucoseelectrolyte powder to treat simple ailments in the home.

\section{INFANT WELFARE CLINIC}

"Road to Health" cards are carried by most mothers. This practice was introduced with remarkable ease, and mothers seem to appreciate the regular monitoring of their children even when healthy. There are about 10000 under-12s in the camp and about 80 births a month. Special effort has been put into providing a service for "at-risk" children-those with

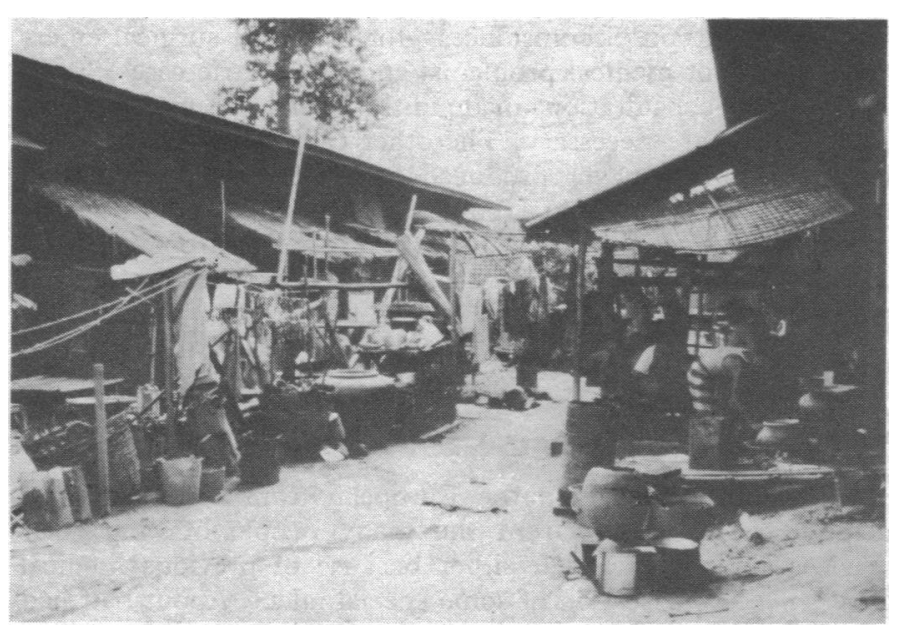

Street in Ubon Refugee Camp.

malnutrition, congenital defects, and adverse social circumstances. We estimate that about $5 \%$ of the children are severely malnourished. A staff of 10 Laotian women run the clinic, with a European nurse, and perform home visits to explain to mothers how to manage their malnourished children. The home visits contribute greatly to understanding how malnutrition occurs and in reducing the size of the problem. After much trial and error, nasogastric-tube feeding using soya milk proved the most effective treatment for severe protein-energy malnutrition. Laotian mothers soon learned to do the feeding themselves. Unfortunately soya milk is not so easy to get as the ubiquitous dried skimmed milk, which is not so culturally acceptable in south-east Asia because it often causes diarrhoea.

\section{INTERPRETERS}

Each European has an interpreter and for all of us it has been a revelation. The disadvantages are obvious, but there are unexpected rewards, particularly with health education. While the doctor records the history and examines a child with diarrhoea, for example, the interpreters discuss prevention and public health with the mother. As most patients are seen in a large room holding up to 50 people waiting to see the doctor, the debate often spreads to include all present-more effective health education than formal lectures. As the interpreter is non-medical, the patients are more likely to raise objections and have them answered in a way they understand. Almost all the interpreters are ex-English language teachers who are widely respected in their own community. If it is possible to convince them on a topic, half the battle is won. One failure with the interpreters, however, was that although they dealt with cerebral gnathostomiasis, they persisted in eating raw river fish.

\section{MEDICAL ASSISTANTS}

The four medical assistants worked as "doctors" in the general clinics and covered emergencies at night. They received four years' training in Laos, usually from the military forces. Often good diagnosticians, their treatments tend to be symptomatic. This tendency is encouraged by Laotian patients, who measure the worth of the doctor by the number, variety, and method of administration of the drugs he prescribes. Our initial attempts to introduce glucose-electrolyte solution for the treatment of diarrhoea instead of the accepted tetracycline, diiodohydroxyquinoline, and diphenoxylate were regarded by them at first as nothing short of planned genocide. They were won over, however, when one of the interpreters described the new treatment as being the same as a "drip" and more expensive than the old treatment. The clinic has to compete with the private pharmacies, which continue to sell a popular cold cure -five coloured tablets of ampicillin, chloramphenicol, tetracycline, prednisolone, and, if one is lucky, an aspirin. Reared in this environment, the medical assistants were only slowly won over to preventive medicine. They do manage, however, to see and treat up to 80 patients a morning, whereas the expatriate is wilting after 40 .

\section{ACUPUNCTURE AND DENTISTRY}

Acupuncture and dentistry have to share a room and so operate on alternate days. Both acupuncturists previously conducted pain clinics in Laos in government hospitals. Surprisingly, neither claims to be able to produce analgesia for minor surgery. They have proved their worth, however, in managing intractable headaches, gastritis, and backaches for which the doctors can find no apparent cause. This has saved clinic time and drug costs.

The dentist brought his own portable drill from Laos. He is an ethnic Chinese, who was born in Laos and raised in Vietnam before receiving his degree in Cambodia-he is pessimistic about the chances of democracy surviving in any country that accepts him for resettlement. A dental service is expensive to maintain and may be considered a luxury, but early treatment reduces the morbidity and nutritional deficiencies associated with a mouth full of rotten teeth, and has enormous social benefits for the individual.

\section{Conclusion}

With the development of a primary health care system using volunteers, many refugees have become aware that they can help in improving the health of the community. Health is 
then no longer an abstract concept or a high-technology tower block that inspires fear and awe. Awareness of the problems producing bad health has resulted in people realising that they not only have a responsibility but also have the ability to improve their predicament. A man is more willing to resite a spoilt well when he sees the illness that results if he does not. A mother is less scared of diarrhoea when she takes part in the nursing.

Problems remain, particularly with toilet facilities and rubbish disposal. The build-up of rubbish has been alleviated in several camps with the help of small incinerators, but the problems of servicing toilets remain unsolved. Eye disease requiring minor surge $y$ was a problem but this was effectively dealt with by a visiting Swiss Red Cross team equipped with a mobile operating theatre. Similar visits by a mass $x$-ray unit and a leprosy screening unit were not as successful because the communitybased services had already detected and treated most sufferers.

A heavy reliance on volunteers is an integral part of the system. Perhaps refugee health volunteers are better motivated than others in Third World countries, but eventually we followed the other camps and paid them a nominal salary. This was necessary because their families were suffering from the hours they gave to the community.

Considering the current teaching in favour of primary health care systems, particularly for Third World countries, we were surprised that these lessons were not being more widely implemented. Although the preventive approach is clearly the best for controlling the health problems of a community, it requires a commitment by all the medical teams and volunteers. Without this commitment, staff too easily fall back into familiar hospital routines.

Dr John O'Sullivan and Dr Geraldine O'Sullivan are supported by the Save the Children Fund, and Dr Ebrahim by the Overseas Development Administration. Requests for reprints should be addressed to $\mathrm{Dr} S$ Ebrahim, 7 Broxtowe Street, Sherwood, Nottingham.

\title{
Reading for Pleasure
}

\section{Second time round}

\author{
IAN A D BOUCHIER
}

The Greek poet Odysseus Elytis, who was awarded the 1979 Nobel Prize for literature, commented that his ambition was "simply that young people be able to turn to my books when they feel lonely." He implies a lack of companions, a need for friends; and yet how many of us can turn readily to the shelves of the library or living room and take down a familiar book which will provide us with that undemanding fellowship we require. Reading can be a great comfort, but at times of unease it is not always agreeable to attempt a strange work and this is the occasion when old friends suit best. Even so, I find that there are few books which I can read again, and yet againwhich is in striking contrast to having favourite music, for there are many compositions that give me great satisfaction and to which I return repeatedly. I suspect that this is because music, on the whole, provides a much more immediate, intense and varied experience than does prose.

A second visit to a book is generally an emotional event, for the narrative has become of secondary importance. After all, the surprises have happened, the novelty has gone and, however long the interval, recall is sufficiently accurate to anticipate the development of the plot. But the atmosphere can be experienced afresh, and it is this that I seek when I return to a favourite tale. Implicitly there are books for particular occasions; some can be read at odd moments during a busy week, others are best left to holidays when the days can be uninterrupted, the evenings free for reflection, and the circumstances more favourable for establishing that essential intellectual and emotional harmony with the author and his subject.

\footnotetext{
Department of Medicine, Ninewells Hospital and Medical School, The University of Dundee, Dundee DD1 9SY

IAN A D BOUCHIER, MD, FRCP, professor
}

\section{Of war and want}

No book has had a greater impact on me than Erich Maria Remarque's All Quiet on the Western Front, and this was the first work which I read for the second time. There has been nothing to equal the vivid descriptions of the macabre life of the front-line soldier during the first world war or the attitudes of men towards their grim conditions. The twilight existence, the awfulness of life, and the ambivalence towards death are all sensitively drawn. The book is unusual in that this incomparable account of war was written by a man who had no experience of it, and Remarque is similar to Stephen Crane, who wrote another classic of war, The Red Badge of Courage, and who was born six years after Lee's surrender; he, too, had had no firsthand knowledge of battle when his book was written.

Reading All Quiet on the Western Front had two other consequences for me. It served to introduce me to the rich literature devoted to the Great War and, improbably, helped me to obtain real and lasting pleasure from reading poetry. Since then I have enjoyed, with feeling and admiration, the personal records of Blunden, Graves, and Sassoon; that uniquely Welsh story of the war, In Parenthesis by David Jones; and Henri Barbusse's Under Fire-which recounts the experience of the French soldier. No comparable writing originated from the second world war, probably because the battles were fought differently and the attitudes of the men and their commanders had changed. I was not too young to appreciate the major events of this conflict, but it was as an adult that I first became aware of the carnage of the Great War and wondered how the soldiers endured the trenches and the lottery of going over the top. I still find it hard to understand what resources of mind and character enabled these men to remain sane. Many years later Paul Celan cried passionately for those who "have drunk the milk of darkness," but few authors portray the pity and futility of war with as much insight as Remarque.

The war poetry of $1914-18$ is simple, direct, and moving. 